\title{
Atrial fibrillation and silent stroke: links, risks, and challenges
}

This article was published in the following Dove Press journal:

Vascular Health and Risk Management

7 March 2016

Number of times this article has been viewed

\section{Kathrin Hahne' \\ Gerold Mönnig² \\ Alexander Samol' \\ 'Division of Cardiology, ${ }^{2}$ Division of Electrophysiology, Department of \\ Cardiovascular Medicine, University \\ Hospital Münster, Münster, Germany}

\begin{abstract}
Atrial fibrillation (AF) is the most common cardiac arrhythmia, with a projected number of 1 million affected subjects in Germany. Changes in age structure of the Western population allow for the assumption that the number of concerned people is going to be doubled, maybe tripled, by the year 2050. Large epidemiological investigations showed that AF leads to a significant increase in mortality and morbidity. Approximately one-third of all strokes are caused by $\mathrm{AF}$ and, due to thromboembolic cause, these strokes are often more severe than those caused by other etiologies. Silent brain infarction is defined as the presence of cerebral infarction in the absence of corresponding clinical symptomatology. Progress in imaging technology simplifies diagnostic procedures of these lesions and leads to a large amount of diagnosed lesions, but there is still no final conclusion about frequency, risk factors, and clinical relevance of these infarctions. The prevalence of silent strokes in patients with AF is higher compared to patients without AF, and several studies reported high incidence rates of silent strokes after AF ablation procedures. While treatment strategies to prevent clinically apparent strokes in patients with AF are well investigated, the role of anticoagulatory treatment for prevention of silent infarctions is unclear. This paper summarizes developments in diagnosis of silent brain infarction and its context to AF.
\end{abstract}

Keywords: atrial fibrillation, silent strokes, cardiac embolic events, stroke risk

\section{Introduction}

Atrial fibrillation (AF) is the most common cardiac arrhythmia, affecting an estimated $1 \%$ of the population. ${ }^{1}$ Its prevalence increases age dependently, from $<0.1 \%$ in adults younger than 55 years to $8 \%$ in persons aged 80 years or older. ${ }^{1}$ Approximately every fourth person over 40 years will suffer from AF in his or her life. ${ }^{2}$ Changes in the age structure of Western populations lead to the assumption that the number of affected patients will at least duplicate by the year $2050 .{ }^{1}$ Large trials and epidemiological investigations showed a doubled increase in mortality in AF patients, ${ }^{3,4}$ including patients with "silent AF". ${ }^{5}$ Approximately one-third of all strokes are caused by AF, and AF-caused strokes are often more severe than non-AF-related strokes. ${ }^{6-9}$ Data from the Framingham Study showed a three- to five fold increased risk of stroke in AF patients. ${ }^{10,11}$ AF often occurs with no or only few symptoms and is therefore often undiagnosed or only diagnosed when complications like stroke or heart failure occur. ${ }^{5,12}$ On the other hand, many studies reported a significantly higher percentage of silent strokes in AF patients diagnosed by different methods of cerebral imaging compared to patients without AF history. ${ }^{13-16}$ Effective oral anticoagulation (OAC) therapy can decrease the rate of stroke up to $80 \%$ in $\mathrm{AF} .{ }^{17}$
Correspondence: Alexander Samol Department of Cardiology and Critical Care Medicine, Johannes Wesling Hospital Minden, Hans-Nolte-Str I, 32429 Minden, Germany

Tel +4957I 79053102

Fax +4957I 790293100

Email Alexander.Samol@

muehlenkreiskliniken.de
Vascular Health and Risk Management 2016:12 65-74

(c) (i) (2) ๑) 2016 Hahne et al. This work is published and liensed by Dove Medical Press Limited. The full terms of this license are available at https://www.dovepress.com/terms. (c). you hereby accept the Terms. Non-commercial uses of the work are permitted without any further permission from Dove Medical Press Limited, provided the work is properly attributed. For permission for commercial use of this work, please see paragraphs 4.2 and 5 of our Terms (https://www.dovepress.com/terms.php).
Dovepress

http://dx.doi.org/| 0.2147/VHRM.S8|807
65 
Silent cerebral infarction (SCI) is defined as the presence of cerebral infarction in the absence of corresponding clinical symptomatology. SCI is a part of cerebral small-vessel disease, which includes white matter hyperintensities and cerebral microbleeds. ${ }^{18}$ Progress in imaging technology simplifies diagnostic procedures of these lesions. There is still no final conclusion about frequency, risk factors, and clinical relevance of these lesions.

AF patients with silent and hitherto undiagnosed stroke are often not treated with oral anticoagulants, and the impact of this therapy on SCIs remains unclear and needs further investigation. ${ }^{19}$

\section{Silent stroke and silent cerebral lesions \\ Prevalence and incidence of silent strokes in common populations}

In 1965 Fisher $^{20}$ first described cerebral infarction without any clinic symptoms. Studies of the past years showed that these lesions are not as benign as originally thought. ${ }^{21}$ In long-term analyses, these lesions correlate with neurological and cognitive deficits and psychiatric disorders in elderly patients. ${ }^{21}$ Silent cerebral ischemia is now recognized as part of a spectrum of cerebrovascular disease, which also includes transient ischemic attack (TIA) and stroke. ${ }^{18} \mathrm{~A}$ change in terminology to "covert infarction" is in discussion..$^{22}$

Depending on the definition of stroke, prevalence of SCI can range. A prevalence of $10.7 \%$ was mentioned in the Framingham Offspring study ${ }^{23}$ In this study, stroke was defined by clinical symptoms for more than 24 hours. Most remaining published community sample studies showed a prevalence between $10 \%$ and $20 \%$. In Routine Health Care Studies, an SCI range between $5 \%$ and $62 \%$ has been reported. ${ }^{21}$ Incidence data are rare. Rates from $1.9 \%$ to $3.7 \%$ per year are reported, with patients age being an important risk factor for SCI. ${ }^{21}$ Uehara et $\mathrm{al}^{24}$ showed that $8 \%$ of the $60-69$ year old participants had new lesions over the duration of follow-up and that $22 \%$ of those patients were older than 80 years. The Rotterdam Scan Study examined 1,077 patients without clinical symptoms or history of stroke. Statistical analyses showed an increased risk of $8 \%$ per year for an SBI after reaching the age of 60 years. ${ }^{25}$ In conclusion, SCIs are approximately ten times more frequent than a stroke. ${ }^{26}$

\section{Diagnosis of $\mathrm{SCl}$}

Most studies use diffusion-weighted magnetic resonance imaging (DW-MRI). Data show a significantly higher sensitivity to detect lesions than computed tomography (CT)..$^{27,28}$
Information from earlier studies using autopsy is unclear because of the limited sensitivity to detect small lesions due to thick slices and large interslice gaps. ${ }^{29}$

Cerebral ischemia can be detected within minutes after onset by detection of a hyperintense lesion on DWI indicating cellular edema and hypointense presentation in apparent diffusion coefficient (ADC) map. In contrast to ADC map detection, the T2-weighted fluid-attenuated inverse recovery sequence (FLAIR) turns positive in delay. ${ }^{30}$ To distinguish silent brain infarction from dilated Virchow-Robin spaces and leukaraiosis, additional criteria include a lesion size of $3 \mathrm{~mm}$ or greater and presence of a hyperintense rim around the hypointense lesion on FLAIR images..$^{29,31}$

Further improvement in imaging modalities gives the possibility of further subclassification of silent brain infarction. A silent cerebral event (SCE) is defined as an acute new hyperintense DWI-lesion with reduced ADC.$^{30}$ Recent publications renounce FLAIR positivity because of delayed detection and reduced sensitivity for early diagnosis of SCI. ${ }^{32}$ FLAIRpositive MRI lesions were differentiated as silent cerebral lesions (SCLs; Figures 1 and 2). The best time point for brain MRI evaluation of SCI in asymptomatic patients is still unclear. ${ }^{30}$

Most silent infarctions are localized in the subcortex. ${ }^{33}$ Only $10 \%$ of infarctions are localized in the cortex. ${ }^{26}$ Location of infarction could at least partly explain symptomatic versus covert lesions, because infarction in the internal capsule is associated with a higher probability of symptoms compared to those in other brain regions. Sizes of lacunas were not related to symptoms in studies. ${ }^{20,34}$ Valdés-Hernández et a ${ }^{34}$ showed that the number of silent infarctions correlates with the risk of clinical stroke. ${ }^{34}$

\section{Risk factors for $\mathrm{SCl}$}

Data about risk factors are obtained from community-based samples. Risk factors with a strong association with SCI are age, hypertension, metabolic syndrome, carotid artery disease, and chronic kidney disease. ${ }^{21,35}$ The most clear risk factor is age. A meta-analysis by Fanning et $\mathrm{al}^{21}$ showed an OR of prevalent SCI assessed per year of age ranging from 1.03 (95\% CI: $0.98,1.08)$ to $1.13(95 \%$ CI: $1.09,1.18)$ and per decade ranging from 2.44 (95\% CI: 1.84, 3.23) to $3.21(95 \%$ CI: $2.17,4.74)$. Hypertension resulted in a microangiopathy of several organ systems. Chronic kidney disease and cerebral microangiopathy with lacunar infarction is the final common pathway of hypertension. ${ }^{18}$

Other demographic characteristics and their risk for SCI are still in discussion: The Rotterdam Scan Study and the Cardiovascular Health Study identified a 30\%-40\% increased 


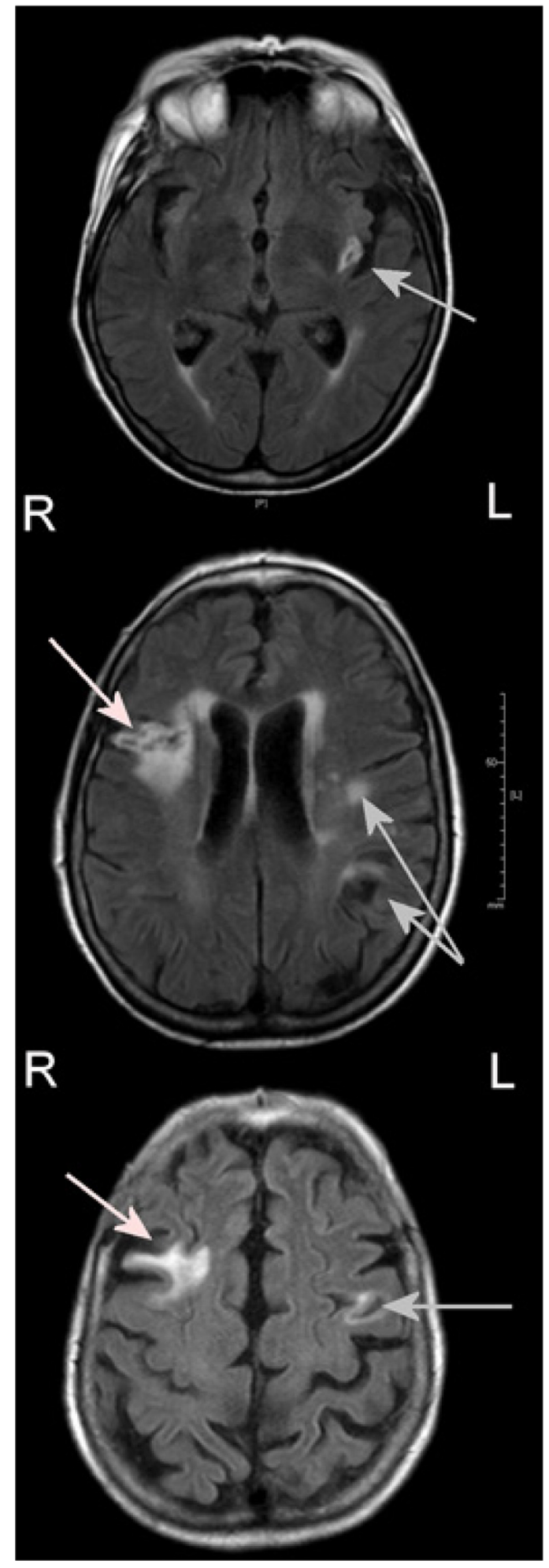

Figure I MRI (FLAIR-weighted sequence) of a 76-year-old patient with chronic atrial fibrillation.

Notes: Approximately 3 years ago, cortical stroke on the right side (white arrow) Silent brain infarction on the left side without clinical symptoms (gray arrow). With kind permission from Springer Science + Business Media: Nervenarzt, Silent brain infarctions, Volume 82(8), 20I I, pages 1043-1052, Ritter MA, Dittrich R, Ringelstein EB. (C) Springer-Verlag 2011. ${ }^{103}$

Abbreviations: FLAIR, fluid-attenuated inversion recovery; MRI, magnetic resonance imaging.

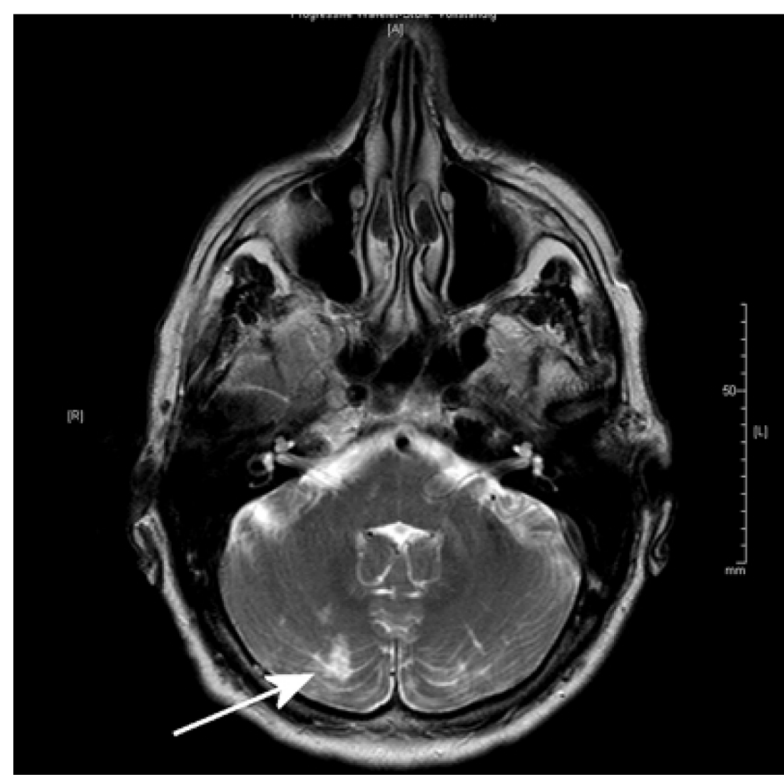

Figure 2 MRI of a 6I-year-old patient with embolic silent brain infarction in cerebellum (arrow).

Note: With kind permission from Springer Science + Business Media: Nervenarzt, Silent brain infarctions, Volume 82(8), 20II, pages 1043-1052, Ritter MA, Dittrich R, Ringelstein EB. (C) Springer-Verlag 2011. ${ }^{103}$

Abbreviation: MRI, magnetic resonance imaging.

prevalence in females. ${ }^{36,37}$ Fukuda et $\mathrm{al}^{38}$ showed a fourfold increased risk for SCI in early menopausal women. The majority of studies do not support any disparity between the sexes, so the effects of this factor remain unclear. ${ }^{21}$

A low alcohol consumption is associated with a reduced risk of stroke morbidity and mortality. ${ }^{39}$ Lee et a ${ }^{40}$ (one or two times a week) and Mukamal et a ${ }^{41}$ (one to six standard drinks per week) showed a protective effect for mild consumption. However, data are inconsistent. Data from Japan showed an increased risk of SCI associated with alcohol consumption, so perhaps ethnic differences in alcohol metabolism may play a role in the risk profile. ${ }^{21,42}$

There are only few studies showing a statistically significant association between smoking and SCI. Howard et $\mathrm{al}^{43}$ showed in 1998 a relationship between exposure to cigarette smoke and SCI, in accordance to the higher incidence of carotid atheroscerlosis. In a cohort of 432 females, an association between "natural" early menopause and SCI was shown. Cigarette smoking, malnutrition, and lower socioeconomic status have been associated with earlier menopause. ${ }^{38}$

Larger studies like the Rotterdam Study showed an association between the presence of diabetes mellitus and pack-years of smoking with symptomatic, but not with silent, infarcts. ${ }^{44}$ In conclusion, the relevance of smoking remains unclear actually.

Abdominal obesity seems to be a risk factor for SBI too. Park et $\mathrm{a}^{45}$ showed an increased risk for SCI for patients 
with a waist circumference $\geq 102 \mathrm{~cm}$ (male) or $\geq 88 \mathrm{~cm}$ (female). Studies analyzing body mass index data showed conflicting results. In a study by Bokura et al, ${ }^{46}$ a body mass index $\geq 25 \mathrm{~kg} / \mathrm{m}^{2}$ was accompanied with a higher risk for SCI. This study only included patients with a metabolic syndrome. Other studies could not confirm these results. ${ }^{21,47}$ In conclusion, an abdominal obesity in the context of a metabolic syndrome seems to be a more important risk factor than other forms of obesity.

\section{$\mathrm{SCls}$ - not so silent?}

SCI can be seen as a part of cerebrovascular disease with a long-term worsening in brain function. Liebetrau et $\mathrm{al}^{48}$ showed, in 2004, that almost one-fifth of 239 85-year-old participants have infarctions on CT, half of them had no clinical symptoms. These infarctions were related to an increased rate of dementia and 3-year mortality. Data from other large studies confirm these findings. ${ }^{36,49,50}$

Patients recognizing stroke symptoms are a prerequisite to differentiate between SCI and TIA or stroke. A study of Howard et $\mathrm{al}^{51}$ in 2006 including 18,462 participants without stroke anamnesis showed that $17.8 \%$ had in history one or more stroke symptoms after exact neurological anamnesis. Ethnic group, income, and educational level can influence detection of physical symptoms. ${ }^{51}$ Furthermore, patients exclude symptoms, for example, for fear of severely diseases. Ritter et $\mathrm{al}^{26}$ showed in their study that theoretical knowledge of symptoms and action knowledge were not found to be significantly associated with shorter prehospital times.

Data from Song et al ${ }^{52}$ presented an increased severity of cognitive decline in patients with Alzheimer's disease and SCI compared to patients with Alzheimer's disease. ${ }^{52}$

Yamashita et $\mathrm{al}^{53}$ demonstrated in a long-term follow-up study that the presence of SCI was associated with a poor prognosis in geriatric depression compared with depressive patients without infarction. Similar to these findings, Fujikawa et $\mathrm{al}^{54}$ showed that for late-onset mania beginning after age of 50 , the incidence of SCI was significantly higher than that of patients with early-onset affective disorders $(P<0.05)$.

Several studies showed an increased risk of stroke after detecting SCI or subcortical white matter lesions. ${ }^{55-57}$ To avoid stroke with severe functional impairment, an improved diagnosis with optimized scoring systems and optimized prevention treatment is necessary. ${ }^{22,58}$

\section{$\mathbf{S C l}$ in AF}

AF was identified as an independent predictor of SCI in a large autopsy study in Japan. ${ }^{33}$ During the last decades, a couple of studies investigated the relationship between AF and the occurrence of SCI diagnosed by different methods of brain imaging. A large number of patients were evaluated using cranial CT. More than 2,000 probands were enrolled in diagnostic studies; SCI rates between $15 \%$ and $50 \%$ in AF patients were observed, ${ }^{15,59-61}$ and a stroke rate of $7 \%$ during a follow-up period of 3 years in AF patients has been reported. ${ }^{59}$ In collectives without a history of stroke and TIA, SCI prevalence was lower compared to collectives without exclusion of these high-risk patients. It seems that the influence of AF duration is not of clinical relevance; the prevalence between paroxysmal and chronic AF patients did not significantly vary. ${ }^{61}$ Petersen et al were not able to show a higher SCI rate in patients with AF compared to patients without AF, but they found a significantly higher prevalence of regions with white matter tissue loss in AF patients compared to patients without $\mathrm{AF}^{61}$ Raiha et al ${ }^{14}$ investigated the relationship between vascular factors and white matter low attenuation (WMLA) of the brain in CT and found a prevalence of WMLA of $73 \%$ in a small subgroup of 30 patients with AF compared to $48 \%$ in non-AF patients. In recent years, several studies investigated the relationship between SCI diagnosed by MRI and AF: The Framingham Offspring Study showed an increased risk of midlife SCI in patients with AF (OR 2.16) by MRI scan. ${ }^{23}$ In dependence of different scan techniques and sequences and their specific image resolution, SCI rates in AF patients between $12.3 \%$ and $92 \%$ have been reported compared to rates between $17 \%$ and $69 \%$ in non-AF patients. ${ }^{16,62-64}$ Gaita et $\mathrm{al}^{13}$ found an SCI rate of $92 \%$ in patients with persistent $\mathrm{AF}$, a rate of $89 \%$ in patients with paroxysmal AF, and a rate of $46 \%$ in patients without AF, and thus was also not able to show a relationship between SCI prevalence and AF duration. ${ }^{13}$ In a subgroup of patients with type 2 diabetes mellitus, SCI rates of $61 \%$ in patients with silent AF were reported compared to $29 \%$ in patients without silent $\mathrm{AF}(P<0.01) .{ }^{62,65}$ Thus, the prevalence of SCI in AF patients is higher than in controls, albeit the prevalence varies widely between the different studies. The prevalence seems to be dependent on the sensitivity of the diagnostic tool and the comorbidities of the investigated collective. Table 1 summarizes sample sizes and event rates of the different studies.

\section{Silent stroke and aortic or AF-related left atrial appendage abnormalities}

The relationship between AF and SCI is not completely understood. Kobayashi et $\mathrm{al}^{63}$ assumed a synergistic effect of microthrombi and hemodynamic abnormalities. In patients with AF, risk factors for clinically symptomatic thromboembolism have been identified: The SPAF III study identified left 
Table I Summary of SCl studies in patients with AF

\begin{tabular}{|c|c|c|c|c|c|c|}
\hline $\begin{array}{l}\text { Diagnostic } \\
\text { tool }\end{array}$ & Year & Study & Participants & Study design & SCls & $\begin{array}{l}P \text {-value AF vs } \\
\text { non-AF }\end{array}$ \\
\hline Autopsy & 1995 & Shinkawa et $\mathrm{a}^{33}$ & 966 (AF\% unknown) & $\begin{array}{l}\text { Nonstroke vs silent stroke } \\
\text { vs stroke }\end{array}$ & 125 (12.9\%) & $\begin{array}{l}P<0.05 \text { (nonstroke } \\
\text { vs silent stroke }\end{array}$ \\
\hline \multirow[t]{5}{*}{ CT } & 1987 & Petersen et $\mathrm{al}^{|6|}$ & 58 (50\% AF) & $\begin{array}{l}\text { Patients with } A F>I \text { year vs } \\
\text { patients with no } A F \text { history }\end{array}$ & $\begin{array}{l}\text { I4 (48\%) in AF vs } 8(28 \%) \\
\text { in non-AF }\end{array}$ & $P>0.1$ \\
\hline & 1988 & Kempster et al ${ }^{15}$ & 222 (24\% AF) & $\begin{array}{l}\text { Patients with } A F>I \text { year vs } \\
\text { patients without } A F\end{array}$ & $\begin{array}{l}7(13 \%) \text { in } A F \text { vs } 7(4 \%) \\
\text { in non-AF }\end{array}$ & $P<0.05$ \\
\hline & 1993 & Raiha et al $\left.\right|^{14}$ & 204 (I5\% AF) & $\begin{array}{l}\text { Records with CT scans } \\
\text { from one hospital }\end{array}$ & $\begin{array}{l}73 \% \text { in } \mathrm{AF} \text { vs } 48 \% \text { in } \\
\text { non-AF }\end{array}$ & $P=0.00959$ \\
\hline & 1995 & Ezekowitz et a ${ }^{59}$ & $516(100 \%$ AF $)$ & $\begin{array}{l}\text { Patients with } \\
\text { nonrheumatic AF }\end{array}$ & $\begin{array}{l}\text { I4.7\% at baseline } \\
\text { Between } 1.01 \% \\
\text { and } 1.57 \% \text { during FU }\end{array}$ & - \\
\hline & 1996 & EAFT Study Group ${ }^{60}$ & 985 (I00\% AF) & $\begin{array}{l}\text { Patients with nonrheumatic } \\
\text { AF and history of TIA or } \\
\text { nondisabling ischemic stroke }\end{array}$ & $14 \%$ & - \\
\hline \multirow[t]{7}{*}{ MRI } & 2008 & Das et $\mathrm{al}^{23}$ & 2,040 (2.2\% AF) & $\begin{array}{l}\text { Longitudinal } \\
\text { community-based study }\end{array}$ & $\begin{array}{l}220 \text { with } \mathrm{SCl}(5 \% \mathrm{AF}) \\
\mathrm{I}, 820 \text { without } \mathrm{SCl} \\
(\mathrm{I} .9 \% \mathrm{AF})(\mathrm{HR} 2.16)\end{array}$ & $P=0.033$ \\
\hline & 2011 & Neumann et al ${ }^{82}$ & 89 (I00\% AF) & Single-center study & $12.3 \%$ & - \\
\hline & 2012 & Kobayashi et al ${ }^{63}$ & 142 (50\% AF) & $\begin{array}{l}\text { Patients with nonvalvular } \\
A F \text { vs controls without } A F\end{array}$ & $\begin{array}{l}74.6 \% \text { in } \mathrm{AF} \\
57.7 \% \text { in non-AF }\end{array}$ & $P=0.03$ \\
\hline & 2013 & Gaita et $\mathrm{al}^{13}$ & $\begin{array}{l}270 \text { (I } 80 \text { with } \mathrm{AF}, 50 \% \\
\text { paroxysmal, } 50 \% \\
\text { persistent } \mathrm{AF} \text { ) }\end{array}$ & $\begin{array}{l}\text { Patients with paroxysmal AF } \\
\text { vs persistent AF vs controls }\end{array}$ & $\begin{array}{l}89 \% \text { in paroxysmal AF } \\
\text { vs } 92 \% \text { in persistent AF } \\
\text { vs } 46 \% \text { in controls }\end{array}$ & $\begin{array}{l}P=0.59 * \\
P<0.0 I * *\end{array}$ \\
\hline & 2013 & Stefansdottir et al ${ }^{16}$ & $\begin{array}{l}4,25 \text { I (330 with } \\
\text { AF [8\%]) }\end{array}$ & Longitudinal study & $\begin{array}{l}48.8 \% \text { in } \mathrm{AF} \text { vs } 28.6 \% \\
\text { in non- } \mathrm{AF}\end{array}$ & $P<0.001$ \\
\hline & 2013 & Marfella et $a^{65}$ & 464 (38\% AF) & $\begin{array}{l}\text { Longitudinal observational } \\
\text { study, FU over } 37 \text { months } \\
\text { for stroke events }\end{array}$ & $\begin{array}{l}\text { Baseline } \mathrm{SCl} 6 \mathrm{I} \% \text { in } \mathrm{AF} \\
\text { vs } 29 \% \text { in non-AF } \\
\text { stroke events during } \mathrm{FU} \\
17.3 \% \text { in } \mathrm{AF} \text { vs } 5.9 \% \\
\text { in non-AF }\end{array}$ & $\begin{array}{l}P<0.0 \mathrm{I}^{* * *} \\
P<0.0 \mathrm{I}^{+}\end{array}$ \\
\hline & 2014 & Chen et a $\mathrm{l}^{64}$ & 935 (48 with AF) & Prospective cohort study & $\begin{array}{l}33.3 \% \text { in } \mathrm{AF} \text { vs } \\
17.3 \% \text { in non- } \mathrm{AF}\end{array}$ & $?$ \\
\hline
\end{tabular}

Notes: ${ }^{*} P$-value paroxysmal vs persistent AF. ${ }^{*} * P$-values paroxysmal AF vs controls and persistent AF vs controls. ${ }^{* * *}$ Baseline $P$-value AF vs non-AF. ${ }^{+}$FU $P$-value AF vs non-AF.

Abbreviations: AF, atrial fibrillation; CT, computed tomography; FU, follow-up; MRI, magnetic resonance imaging; SCI, silent cerebral infarction; vs, versus; TIA, transient ischemic attack; HR, hazard ratio.

atrial abnormalities like a left atrial thrombus, spontaneous echo contrast (SEC), or an abnormal left atrial appendage (LAA) emptying velocity ${ }^{66}$ and also aortic abnormalities like large ( $\geq 4 \mathrm{~mm}$ ), ulcerated, or mobile plaques as risk factors for clinically symptomatic thromboembolisms, all investigated by transesophageal echocardiography (TEE) ${ }^{66}$ However, the mechanisms leading to SCI in patients with nonvalvular AF are not well investigated. Very recently, one study investigated the role of left atrial or aortic abnormalities diagnosed by TEE in silent stroke: Sugioka et al ${ }^{67}$ identified a higher prevalence of SCI in patients with left atrial abnormalities compared to patients without left atrial abnormalities $(58 \%$ vs $22 \% ; P<0.001)$ and in patients with complex arch plaques compared to patients without arch plaques $(74 \%$ vs $20 \% ; P<0.001)$. Left atrial abnormalities and complex arch plaques were independent risk factors of SBI. ${ }^{67}$ Thus, abnormalities in the left atrium and complex arch plaques could play an important role in the occurrence of SCI. The authors only found a low prevalence of left atrial thrombus formation, but much higher rates of SEC or abnormal low emptying velocities in the LAA. ${ }^{67}$ Some studies identified SEC as a risk factor of thromboembolism. ${ }^{66,68,69}$ Possible mechanisms are an SEC-related fibrinogen-mediated erythrocyte aggregation ${ }^{70}$ and microembolization of small thrombi arising in the fibrillating LAA. ${ }^{13,71}$

\section{$\mathrm{SCl}$ related to $\mathrm{AF}$ ablation procedures}

Pulmonary vein isolation (PVI) has become a standard therapeutic strategy in the treatment of symptomatic $\mathrm{AF}^{72}$ Complication rates of 3\%-5\% have been reported, with procedure-associated stroke being one of the most severe complications occurring in less than $1 \% .{ }^{73} \mathrm{~A}$ large survey of more than 1,000 procedures reported an occurrence of acute stroke in $0.6 \% .{ }^{74}$ The incidence of SCI varies widely more or less 
dependent of the ablation technology. Within the framework of studies, postablation MRI was performed in more than 1,700 patients and SCI/SCL rates of $12.6 \%$ were derived, with an estimated incidence of $9.3 \%$ after irrigated radiofrequency (IRF) ablation and of $20.9 \%$ using phased duty-cycled radiofrequency pulmonary vein ablation catheter (PVAC) ${ }^{30}$ The largest group of SCL or SCE investigations were patients after IRF pulmonary vein ablation with rates between $7.4 \%$ and $24 \% ;^{75-77}$ the incidence of FLAIR-independent SCE was reported between $6.8 \%$ and $24 \%,{ }^{78-84}$ with lower incidence in patients under continued OAC. ${ }^{81,82}$ Table 2 summarizes the incidence rates and study details.

The number of investigated patients after PVAC procedure is quite smaller. In 2011, three independent studies reported incidence rates of SCE/SCL $>35 \% .^{75,77,79}$ Modifications in ablation procedure led to a significant reduction in SCE/SCL, with lowest rates in the ERACE trial (Table 2). ${ }^{32,85,86}$ They revealed an incidence of only $1.7 \%$, which is the lowest incidence rate of any ablation technology so far by three specific procedural changes: 1) the procedure was performed under heparin application (activated clotting time (ACT)>350 ms) and under continued OAC; 2 ) they minimized air ingress; and 3 ) they deactivated the distal or proximal electrode to avoid radiofrequency interaction. ${ }^{86}$

The number of investigated patients after cryoballoon ablation is the smallest one compared to the previously reported ablation techniques, with an incidence of SCL/ SCE of $14.5 \% .^{30} \mathrm{SCL}$ incidence rates were lowest after cryoballoon ablation, followed by IRF ablation and highest after PVAC ablation. ${ }^{13,75}$ Thus, all actually used ablation techniques of AF lead to an periprocedural occurrence of new SCI, but the clinical relevance of these lesions is unclear and not well investigated. Table 2 summarizes the results of published studies.

The intraprocedural application of heparin to avoid thrombembolic complications monitored by measurements of ACT is recommended. One study identified ACT values $>320$ seconds as the only independent predictor of SCLs, an ACT increase of one point led to a reduction of stroke risk of $0.4 \% .{ }^{87}$ Another study reported a threefold increase in SCLs if only one ACT value of $<300$ seconds was measured. ${ }^{76}$ They also identified the waiving of heparin bolus before transseptal punctuation as risk factor for SCL. ${ }^{88}$ In contrast to this finding, a second study reported no influence of mean or minimal ACT on occurrence of SCI under continued intake of OAC. ${ }^{81}$

A stable antithrombotic milieu during the ablation procedure is useful to avoid complication. Several studies reported lower periprocedural complication rates if OAC was continued. ${ }^{89-91}$ A couple of studies showed that continuation of OAC leads to lower SCL rates: Gaita et $\mathrm{al}^{92}$ reported a more than threefold increased risk of SCL if INR values below 2.0 were measured. Comparable results were reported on continuation of rivaroxaban intake without an increase of bleeding complications. ${ }^{93}$ In contrast to these findings, Martinek et $\mathrm{al}^{81}$ concluded that continuation of OAC is not able to prevent cerebral embolism. Data of other direct oral anticoagulants (DOAC) are sparse, but similar results as reported for rivaroxaban are hypothesized.

In fact, no periprocedural monitoring system for SCI exists; a few studies tried to detect periprocedural microembolic events by continuous registration of transcranial Doppler (TCD) signals, but a relationship between occurrence of periprocedural microembolic events in TCD and the detection of SCI in MRI after the procedure has not been reported yet. ${ }^{30,94}$ Kochhäuser et al ${ }^{95}$ reported a significantly increased number of periprocedural microembolic events during PVI using PVAC compared to IRF procedure, but they were not able to detect any differences in neuropsychological assessment between the different ablation techniques, and they only found a subtle, diffuse postprocedural impairment of neuropsychological function depending on age and the number of detected microembolic events. Thus, the role of microembolic events as a potential cause of SCI remains unclear and actually not well investigated.

There is low evidence that waiving or postponing of periprocedural electrical cardioversion may decrease the rates of SCI, ${ }^{92}$ but the majority of studies were not able to identify electrical cardioversion as a risk factor for SCI. ${ }^{76,78,80,96}$

\section{Is there a need to reform anticoagulatory treatment regimes?} Kobayashi et $\mathrm{al}^{63}$ showed in a patient group of 79 persons with AF that the $\mathrm{CHADS}_{2}$ score was associated with the number of SCIs in cortex/subcortex. There was no correlation with other infarct locations. Reviewed by Kalantarian et al, ${ }^{29}$ data showed a twofold-increased risk in the odds of SCI.

Anticoagulation is able to reduce symptomatic stroke or TIA significantly in patients with AF. The impact on prevention of SCI is unclear. Further studies are necessary to find out whether anticoagulation influences SCI and identify patients who benefit from anticoagulation or antiplatelet therapy. ${ }^{29}$ There is low evidence that warfarin is not able to reduce brain volume loss in AF patients, ${ }^{16}$ and differences in cognitive decline in AF patients between warfarin, aspirin, or no treatment could not be reported. ${ }^{97}$ However, a statistically nonsignificant trend toward warfarin treatment versus aspirin 
Table 2 Summary of SCI studies after different ablation techniques of PVI

\begin{tabular}{|c|c|c|c|c|c|c|c|}
\hline $\begin{array}{l}\text { Ablation } \\
\text { technology }\end{array}$ & Year & Study & Participants & Study design & $\begin{array}{l}\text { MRI } \\
\text { Sequences }\end{array}$ & SCls & $P$-value \\
\hline $\begin{array}{l}\text { IRF vs PVAC } \\
\text { vs CB }\end{array}$ & 2011 & $\begin{array}{l}\text { Herrera Siklody } \\
\text { et } \mathrm{a}^{75}\end{array}$ & $\begin{array}{l}74 \text { (IRF 27; PVAC } \\
\text { 24; CB 23) }\end{array}$ & $\begin{array}{l}\text { Prospective, } \\
\text { observational } \\
\text { multicenter study }\end{array}$ & FLAIR, DWI & $\begin{array}{l}\text { IRF } 7.4 \% \\
\text { PVAC } 37.5 \% \\
\text { CB } 4.3 \%\end{array}$ & $P=0.003$ \\
\hline IRF & 2014 & Di Biase et $\mathrm{al}^{76}$ & 428 & $\begin{array}{l}\text { Patients undergoing } \\
\text { PVI (IRF) }\end{array}$ & FLAIR, DWI & $\begin{array}{l}\text { Pre-PVI 43\% (prevalence) } \\
\text { Post-PVI 7.9\% (incidence) }\end{array}$ & - \\
\hline $\begin{array}{l}\text { IRF vs PVAC } \\
\text { vs CB }\end{array}$ & 2011 & Gaita et $\mathrm{al}^{77}$ & $\begin{array}{l}\text { I08 (IRF 36; PVAC } \\
\text { 36; CB 36) }\end{array}$ & $\begin{array}{l}\text { Prospective } \\
\text { observational }\end{array}$ & FLAIR, DWI & $\begin{array}{l}\text { IRF } 8.3 \% \\
\text { PVAC } 38.9 \% \\
\text { CB } 5.6 \%\end{array}$ & $\begin{array}{l}P=0.002^{*} \\
P=0.00 I^{* *} \\
P=0.5^{* * *}\end{array}$ \\
\hline IRF vs $C B$ vs $L B$ & 2014 & Wissner et $\mathrm{al}^{78}$ & $\begin{array}{l}86 \text { (IRF 22; CB 20; } \\
\text { LB 44) }\end{array}$ & $\begin{array}{l}\text { Prospective } \\
\text { observational }\end{array}$ & FLAIR, DWI & $\begin{array}{l}\text { Pre-PVI 57\% (prevalence) } \\
\text { Post-PVI I2.8\% (incidence) }\end{array}$ & $P=0.00959$ \\
\hline IRF and PVAC & 2011 & Deneke et $\mathrm{al}^{79}$ & 86 & $\begin{array}{l}\text { Prospective } \\
\text { observational }\end{array}$ & FLAIR, DWI & Post-PVI 38\% (incidence) & - \\
\hline $\begin{array}{l}\text { RA-PVI } \\
\text { vs manual IRF }\end{array}$ & 2012 & Rillig et al ${ }^{80}$ & 70 (I00\% AF) & $\begin{array}{l}\text { Consecutive patients } \\
\text { with } \mathrm{AF} \text { without TIA } \\
\text { or stroke }\end{array}$ & FLAIR, DWI & $\begin{array}{l}\text { Post-PVI I7\% (RA-PVI I8\% } \\
\text { vs IRF I5\%) }\end{array}$ & $P=n s$ \\
\hline IRF & 2013 & Martinek et a ${ }^{81}$ & 131 (I00\% AF) & $\begin{array}{l}\text { Consecutive patients } \\
\text { with } \mathrm{AF} \text { under } \\
\text { continued OAC }\end{array}$ & DWI & $\begin{array}{l}\text { Post-PVI I2.2\% } \\
\text { (incidence) }\end{array}$ & - \\
\hline CB vs IRF & 2011 & Neumann et a ${ }^{82}$ & 89 (I00\% AF) & Single-center study & DWI & $\begin{array}{l}\text { Pre-PVI I } 2.3 \% \\
\text { Post-PVI 7.9\% (incidence) } \\
\text { (CB 8.9\% vs IRF 6.8\%) }\end{array}$ & $P=\mathrm{ns}$ \\
\hline IRF vs $C B$ vs $L B$ & 2013 & Schmidt et al ${ }^{83}$ & 99 (I00\% AF) & $\begin{array}{l}\text { Prospective } \\
\text { observational }\end{array}$ & DWI & $\begin{array}{l}\text { Post-PVI } 22 \% \text { (incidence) } \\
\text { (IRF } 24.2 \% \text { vs } 18.2 \% \text { vs } \\
\text { LB } 24.2 \% \text { ) }\end{array}$ & $P=\mathrm{ns}$ \\
\hline IRF & 2006 & Lickfett et $a^{84}$ & $20(100 \%$ AF) & $\begin{array}{l}\text { Consecutive patients } \\
\text { with paroxysmal AF }\end{array}$ & DWI & $\begin{array}{l}\text { Post-PVI 10\% } \\
\text { (incidence) }\end{array}$ & - \\
\hline $\begin{array}{l}\text { PVAC (modified } \\
\text { procedure) }\end{array}$ & 2013 & Wieczorek et a $\left.\right|^{85}$ & $120(100 \%$ AF) & $\begin{array}{l}\text { Prospective } \\
\text { observational ( } 50 \% \text { all } \\
\text { electrodes activated vs } \\
50 \% \text { only two electrode } \\
\text { pairs simultaneously } \\
\text { activated) }\end{array}$ & DWI & $\begin{array}{l}\text { Post-PVI } 20 \% \text { (incidence) } \\
\text { (all electrodes } 28.3 \% \\
\text { vs two electrodes } 11.7 \% \text { ) }\end{array}$ & $P=0.039$ \\
\hline PVAC & 2013 & Wieczorek et a $\left.\right|^{85}$ & 37 (I00\% AF) & $\begin{array}{l}\text { Prospective } \\
\text { observational }\end{array}$ & DWI & $\begin{array}{l}\text { Post-PVI } 27 \% \text { (incidence) } \\
\text { ( } 44 \% \text { in patients with } \\
\text { electrode interaction } \\
\text { (EI and EI0) vs II\% } \\
\text { in patients without) }\end{array}$ & $P=0.029$ \\
\hline $\begin{array}{l}\text { PVAC } \\
\text { (three modifications) }\end{array}$ & 2013 & Verma et $\mathrm{al}^{86}$ & 60 (I00\% AF) & $\begin{array}{l}\text { Prospective } \\
\text { observational }\end{array}$ & FLAIR, DWI & $\begin{array}{l}\text { Pre-PVI } 60 \% \text { with lesions } \\
\text { Post-PVI I.7\% (incidence) }\end{array}$ & - \\
\hline
\end{tabular}

Notes: *P-value IRF vs PVAC. **P-value CB vs PVAC. ***P-value $C B$ vs IRF.

Abbreviations: AF, atrial fibrillation; CB, Cryoballoon; DWI, diffusion-weighted imaging; EI, electrode I; EI0, electrode I0; FLAIR, fluid-attenuated inversion recovery; IRF, irrigated radiofrequency; LB, laser balloon; MRI, magnetic resonance imaging; ns, not significant; OAC, oral anticoagulation; PVAC, pulmonary vein ablation catheter; RA-PVI, robot-assisted pulmonary vein isolation; $\mathrm{SCl}$, silent cerebral infarction; vs, versus; TIA, transient ischemic attack.

in one study ${ }^{98}$ and a statistically nonsignificant trend toward OAC and decreased risk of dementia in another study have been reported. ${ }^{99}$ Flaker et al ${ }^{100}$ assumed that less effective $\mathrm{OAC}$ is associated with higher rates of cognitive decline and vascular events in patients with AF under OAC. Thus, DOACs with a higher time in therapeutic range compared to warfarin may prevent SCI.

On the other hand, it is not clearly defined if diagnosed SCI in cerebral asymptomatic AF patients should lead to an increase in $\mathrm{CHA}_{2} \mathrm{DS}_{2}$-VASc score of the subject, and thus this may result in a treatment with OAC only caused by diagnosis of SBI. Gaita et $\mathrm{al}^{13}$ reported SCI rates approximately $90 \%$ in AF patients, while $60 \%$ of these patients had a $\mathrm{CHA}_{2} \mathrm{DS}_{2}-$ VASc score of $\leq 1$, and thus no general recommendation for OAC treatment. ${ }^{13}$ If this therapy regime would prevent strokes in AF patients, MRI screening in AF patients with a $\mathrm{CHA}_{2} \mathrm{DS}_{2}$-VASc score of $\leq 1$ should be discussed.

\section{Conclusion}

Studies showed that silent brain infarction correlate with impaired cognition, neurological deficits, and psychiatric disorder, as well as an increased risk of stroke. These suggest that 
these findings are neither silent nor innocuous. ${ }^{101}$ Especially in elderly people, prevention strategies should be intensified, with a particular focus on the treatment of hypertensive microangiopathy to minimize the risk of eroding brain function and acute stroke. ${ }^{22}$ Targeted education on the warning signs of stroke and risk factor reduction efforts for individuals who report stroke symptoms may be helpful in improving early recognition and in the prevention of stroke. ${ }^{51}$

In studies, especially patients with $\mathrm{AF}$ had a higher rate of SCI and increased risk of stroke. ${ }^{56,102}$ A possible cause is a synergistic effect of microthrombi and hemodynamic abnormalities. ${ }^{56}$ Importance of prophylactic anticoagulation to reduce the incidence of SCI is unclear because of less data. ${ }^{29}$ Periprocedurally occurring SCIs are five to ten times more common than strokes. Consequences for patients are not sufficiently analyzed. Investigation in different interventional techniques is necessary to improve patient's safety.

\section{Disclosure}

The authors report no conflicts of interest in this work.

\section{References}

1. Go AS, Hylek EM, Phillips KA, et al. Prevalence of diagnosed atrial fibrillation in adults: national implications for rhythm management and stroke prevention: the AnTicoagulation and Risk Factors in Atrial Fibrillation (ATRIA) Study. JAMA. 2001;285(18):2370-2375.

2. Lloyd-Jones DM, Wang TJ, Leip EP, et al. Lifetime risk for development of atrial fibrillation: the Framingham Heart Study. Circulation. 2004;110(9):1042-1046.

3. Miyasaka Y, Barnes ME, Gersh BJ, et al. Secular trends in incidence of atrial fibrillation in Olmsted County, Minnesota, 1980 to 2000, and implications on the projections for future prevalence. Circulation. 2006;114(2):119-125.

4. Benjamin EJ, Wolf PA, D'Agostino RB, Silbershatz H, Kannel WB, Levy D. Impact of atrial fibrillation on the risk of death: the Framingham Heart Study. Circulation. 1998;98(10):946-952.

5. Healey JS, Connolly SJ, Gold MR, et al. Subclinical atrial fibrillation and the risk of stroke. $N$ Engl J Med. 2012;366(2):120-129.

6. Bornstein NM, Aronovich BD, Karepov VG, et al. The Tel Aviv Stroke Registry: 3600 consecutive patients. Stroke. 1996;27(10):1770-1773.

7. Kaarisalo MM, Immonen-Raiha P, Marttila RJ, et al. Atrial fibrillation and stroke. Mortality and causes of death after the first acute ischemic stroke. Stroke. 1997;28(2):311-315.

8. Lin HJ, Wolf PA, Kelly-Hayes M, et al. Stroke severity in atrial fibrillation. The Framingham Study. Stroke. 1996;27(10):1760-1764.

9. Marini C, De SF, Sacco S, et al. Contribution of atrial fibrillation to incidence and outcome of ischemic stroke: results from a populationbased study. Stroke. 2005;36(6):1115-1119.

10. Benjamin EJ, Levy D, Vaziri SM, D’Agostino RB, Belanger AJ, Wolf PA. Independent risk factors for atrial fibrillation in a population-based cohort. The Framingham Heart Study. JAMA. 1994;271(11):840-844.

11. Wolf PA, Abbott RD, Kannel WB. Atrial fibrillation as an independent risk factor for stroke: the Framingham Study. Stroke. 1991;22(8):983-988.

12. Samol A, Masin M, Gellner R, et al. Prevalence of unknown atrial fibrillation in patients with risk factors. Europace. 2013;15(5):657-662.

13. Gaita F, Corsinovi L, Anselmino M, et al. Prevalence of silent cerebral ischemia in paroxysmal and persistent atrial fibrillation and correlation with cognitive function. J Am Coll Cardiol. 2013;62(21):1990-1997.
14. Raiha I, Tarvonen S, Kurki T, Rajala T, Sourander L. Relationship between vascular factors and white matter low attenuation of the brain. Acta Neurol Scand. 1993;87(4):286-289.

15. Kempster PA, Gerraty RP, Gates PC. Asymptomatic cerebral infarction in patients with chronic atrial fibrillation. Stroke. 1988;19(8):955-957.

16. Stefansdottir H, Arnar DO, Aspelund T, et al. Atrial fibrillation is associated with reduced brain volume and cognitive function independent of cerebral infarcts. Stroke. 2013;44(4):1020-1025.

17. Wilke T, Groth A, Mueller S, et al. Oral anticoagulation use by patients with atrial fibrillation in Germany. Adherence to guidelines, causes of anticoagulation under-use and its clinical outcomes, based on claimsdata of 183,448 patients. Thromb Haemost. 2012;107(6):1053-1065.

18. Kim BJ, Lee SH. Prognostic impact of cerebral small vessel disease on stroke outcome. J Stroke. 2015;17(2):101-110.

19. Cao L, Pokorney SD, Hayden K, Welsh-Bohmer K, Newby LK. Cognitive function: is there more to anticoagulation in atrial fibrillation than stroke? J Am Heart Assoc. 2015;4(8):e001573.

20. Fisher CM. Lacunes: small, deep cerebral infarcts. Neurology. 1965;15:774-784

21. Fanning JP, Wong AA, Fraser JF. The epidemiology of silent brain infarction: a systematic review of population-based cohorts. BMC Med. 2014;12:119.

22. Longstreth WT Jr, Dulberg C, Manolio TA, et al. Incidence, manifestations, and predictors of brain infarcts defined by serial cranial magnetic resonance imaging in the elderly: the Cardiovascular Health Study. Stroke. 2002;33(10):2376-2382.

23. Das RR, Seshadri S, Beiser AS, et al. Prevalence and correlates of silent cerebral infarcts in the Framingham offspring study. Stroke. 2008;39(11):2929-2935.

24. Uehara T, Tabuchi M, Mori E. Risk factors for silent cerebral infarcts in subcortical white matter and basal ganglia. Stroke. 1999;30(2):378-382.

25. Vermeer SE, Den Heijer T, Koudstaal PJ, et al. Incidence and risk factors of silent brain infarcts in the population-based Rotterdam Scan Study. Stroke. 2003;34(2):392-396.

26. Ritter MA, Brach S, Rogalewski A, et al. Discrepancy between theoretical knowledge and real action in acute stroke: self-assessment as an important predictor of time to admission. Neurol Res. 2007;29(5): 476-479.

27. Morris Z, Whiteley WN, Longstreth WT Jr, et al. Incidental findings on brain magnetic resonance imaging: systematic review and meta-analysis. BMJ. 2009;339:b3016.

28. Lovblad KO, Laubach HJ, Baird AE, et al. Clinical experience with diffusion-weighted MR in patients with acute stroke. AJNR Am J Neuroradiol. 1998;19(6):1061-1066.

29. Kalantarian S, Ay H, Gollub RL, et al. Association between atrial fibrillation and silent cerebral infarctions: a systematic review and meta-analysis. Ann Intern Med. 2014;161(9):650-658.

30. Deneke T, Jais P, Scaglione M, et al. Silent cerebral events/lesions related to atrial fibrillation ablation: a clinical review. J Cardiovasc Electrophysiol. 2015;26(4):455-463.

31. Bokura H, Kobayashi S, Yamaguchi S. Distinguishing silent lacunar infarction from enlarged Virchow-Robin spaces: a magnetic resonance imaging and pathological study. J Neurol. 1998;245(2):116-122.

32. Wieczorek M, Hoeltgen R, Brueck M. Does the number of simultaneously activated electrodes during phased RF multielectrode ablation of atrial fibrillation influence the incidence of silent cerebral microembolism? Heart Rhythm. 2013;10(7):953-959.

33. Shinkawa A, Ueda K, Kiyohara Y, et al. Silent cerebral infarction in a community-based autopsy series in Japan. The Hisayama Study. Stroke. 1995;26(3):380-385.

34. Valdés-Hernández MD, Maconick LC, Munoz Maniega S, et al. A comparison of location of acute symptomatic vs. "silent" small vessel lesions. Int J Stroke. 2015;10(7):1044-1055.

35. Toyoda G, Bokura H, Mitaki S, et al. Association of mild kidney dysfunction with silent brain lesions in neurologically normal subjects. Cerebrovasc Dis Extra. 2015;5(1):22-27. 
36. Vermeer SE, Prins ND, den HT, Hofman A, Koudstaal PJ, Breteler MM. Silent brain infarcts and the risk of dementia and cognitive decline. $N$ Engl J Med. 2003;348(13):1215-1222.

37. Sato R, Bryan RN, Fried LP. Neuroanatomic and functional correlates of depressed mood: the Cardiovascular Health Study. Am J Epidemiol. 1999;150(9):919-929.

38. Fukuda K, Takashima Y, Hashimoto M, Uchino A, Yuzuriha T, Yao H. Early menopause and the risk of silent brain infarction in communitydwelling elderly subjects: the Sefuri brain MRI study. J Stroke Cerebrovasc Dis. 2014;23(5):817-822.

39. Zhang C, Qin YY, Chen Q, et al. Alcohol intake and risk of stroke: a dose-response meta-analysis of prospective studies. Int J Cardiol. 2014;174(3):669-677.

40. Lee SJ, Cho YJ, Kim JG, et al. Moderate alcohol intake reduces risk of ischemic stroke in Korea. Neurology. 2015;85(22):1950-1956.

41. Mukamal KJ, Longstreth WT Jr, Mittleman MA, Crum RM, Siscovick DS. Alcohol consumption and subclinical findings on magnetic resonance imaging of the brain in older adults: the cardiovascular health study. Stroke. 2001;32(9):1939-1946.

42. Fukuda K, Yuzuriha T, Kinukawa N, et al. Alcohol intake and quantitative MRI findings among community dwelling Japanese subjects. J Neurol Sci. 2009;278(1-2):30-34.

43. Howard G, Wagenknecht LE, Cai J, Cooper L, Kraut MA, Toole JF. Cigarette smoking and other risk factors for silent cerebral infarction in the general population. Stroke. 1998;29(5):913-917.

44. Vermeer SE, Koudstaal PJ, Oudkerk M, Hofman A, Breteler MM. Prevalence and risk factors of silent brain infarcts in the populationbased Rotterdam Scan Study. Stroke. 2002;33(1):21-25.

45. Park K, Yasuda N, Toyonaga S, Tsubosaki E, Nakabayashi H, Shimizu K. Significant associations of metabolic syndrome and its components with silent lacunar infarction in middle aged subjects. J Neurol Neurosurg Psychiatry. 2008;79(6):719-721.

46. Bokura H, Yamaguchi S, Iijima K, Nagai A, Oguro H. Metabolic syndrome is associated with silent ischemic brain lesions. Stroke. 2008;39(5):1607-1609.

47. Aono Y, Ohkubo T, Kikuya M, et al. Plasma fibrinogen, ambulatory blood pressure, and silent cerebrovascular lesions: the Ohasama study. Arterioscler Thromb Vasc Biol. 2007;27(4):963-968.

48. Liebetrau M, Steen B, Hamann GF, Skoog I. Silent and symptomatic infarcts on cranial computerized tomography in relation to dementia and mortality: a population-based study in 85 -year-old subjects. Stroke. 2004;35(8):1816-1820.

49. Prins ND, van Dijk EJ, den Heijer T, et al. Cerebral white matter lesions and the risk of dementia. Arch Neurol. 2004;61(10):1531-1534.

50. Saavedra Perez HC, Direk N, Hofman A, Vernooij MW, Tiemeier H, Ikram MA. Silent brain infarcts: a cause of depression in the elderly? Psychiatry Res. 2013;211(2):180-182.

51. Howard VJ, McClure LA, Meschia JF, Pulley L, Orr SC, Friday GH. High prevalence of stroke symptoms among persons without a diagnosis of stroke or transient ischemic attack in a general population: the REasons for Geographic And Racial Differences in Stroke (REGARDS) study. Arch Intern Med. 2006;166(18):1952-1958.

52. Song IU, Kim JS, Kim YI, Eah KY, Lee KS. Clinical significance of silent cerebral infarctions in patients with Alzheimer disease. Cogn Behav Neurol. 2007;20(2):93-98.

53. Yamashita H, Fujikawa T, Takami H, et al. Long-term prognosis of patients with major depression and silent cerebral infarction. Neuropsychobiology. 2010;62(3):177-181.

54. Fujikawa T, Yamawaki S, Touhouda Y. Silent cerebral infarctions in patients with late-onset mania. Stroke. 1995;26(6):946-949.

55. Bokura H, Kobayashi S, Yamaguchi S, et al. Silent brain infarction and subcortical white matter lesions increase the risk of stroke and mortality: a prospective cohort study. J Stroke Cerebrovasc Dis. 2006;15(2):57-63.

56. Kobayashi S, Okada K, Koide H, Bokura H, Yamaguchi S. Subcortical silent brain infarction as a risk factor for clinical stroke. Stroke. 1997;28(10):1932-1939.
57. Vermeer SE, Hollander M, van Dijk EJ, et al. Silent brain infarcts and white matter lesions increase stroke risk in the general population: the Rotterdam Scan Study. Stroke. 2003;34(5):1126-1129.

58. Coutts SB, Eliasziw M, Hill MD, et al. An improved scoring system for identifying patients at high early risk of stroke and functional impairment after an acute transient ischemic attack or minor stroke. Int $J$ Stroke. 2008;3(1):3-10.

59. Ezekowitz MD, James KE, Nazarian SM, et al. Silent cerebral infarction in patients with nonrheumatic atrial fibrillation. The veterans affairs stroke prevention in nonrheumatic atrial fibrillation investigators. Circulation. 1995;92(8):2178-2182.

60. Silent brain infarction in nonrheumatic atrial fibrillation. EAFT Study Group. European Atrial Fibrillation Trial. Neurology. 1996;46(1):159-165.

61. Petersen P, Madsen EB, Brun B, Pedersen F, Gyldensted C, Boysen G. Silent cerebral infarction in chronic atrial fibrillation. Stroke. 1987;18(6):1098-1100.

62. Neumann T, Wojcik M, Berkowitsch A, et al. Cryoballoon ablation of paroxysmal atrial fibrillation: 5-year outcome after single procedure and predictors of success. Europace. 2013;15(8):1143-1149.

63. Kobayashi A, Iguchi M, Shimizu S, Uchiyama S. Silent cerebral infarcts and cerebral white matter lesions in patients with nonvalvular atrial fibrillation. J Stroke Cerebrovasc Dis. 2012;21(4):310-317.

64. Chen LY, Lopez FL, Gottesman RF, et al. Atrial fibrillation and cognitive decline-the role of subclinical cerebral infarcts: the atherosclerosis risk in communities study. Stroke. 2014;45(9):2568-2574.

65. Marfella R, Sasso FC, Siniscalchi M, et al. Brief episodes of silent atrial fibrillation predict clinical vascular brain disease in type 2 diabetic patients. J Am Coll Cardiol. 2013;62(6):525-530.

66. Zabalgoitia M, Halperin JL, Pearce LA, Blackshear JL, Asinger RW, Hart RG. Transesophageal echocardiographic correlates of clinical risk of thromboembolism in nonvalvular atrial fibrillation. Stroke prevention in atrial fibrillation III investigators. J Am Coll Cardiol. 1998;31(7):1622-1626.

67. Sugioka K, Takagi M, Sakamoto S, et al. Predictors of silent brain infarction on magnetic resonance imaging in patients with nonvalvular atrial fibrillation: a transesophageal echocardiographic study. Am Heart J. 2015;169(6):783-790.

68. Pepi M, Evangelista A, Nihoyannopoulos P, et al. Recommendations for echocardiography use in the diagnosis and management of cardiac sources of embolism: European Association of Echocardiography (EAE) (a registered branch of the ESC). Eur J Echocardiogr. 2010;11(6):461-476.

69. Chimowitz MI, DeGeorgia MA, Poole RM, Hepner A, Armstrong WM. Left atrial spontaneous echo contrast is highly associated with previous stroke in patients with atrial fibrillation or mitral stenosis. Stroke. 1993;24(7):1015-1019.

70. Rastegar R, Harnick DJ, Weidemann P, et al. Spontaneous echo contrast videodensity is flow-related and is dependent on the relative concentrations of fibrinogen and red blood cells. J Am Coll Cardiol. 2003;41(4):603-610.

71. Feinberg WM, Seeger JF, Carmody RF, Anderson DC, Hart RG, Pearce LA. Epidemiologic features of asymptomatic cerebral infarction in patients with nonvalvular atrial fibrillation. Arch Intern Med. 1990;150(11):2340-2344.

72. Camm AJ, Kirchhof P, Lip GY, et al. Guidelines for the management of atrial fibrillation: the task force for the management of atrial fibrillation of the European Society of Cardiology (ESC). Eur Heart J. 2010;31(19)2369-2429.

73. Camm AJ, Lip GY, De Caterina R, et al. 2012 focused update of the ESC Guidelines for the management of atrial fibrillation: an update of the 2010 ESC Guidelines for the management of atrial fibrillation. Developed with the special contribution of the European Heart Rhythm Association. Eur Heart J. 2012;33(21):2719-2747.

74. Arbelo E, Brugada J, Hindricks G, et al. ESC-EURObservational Research Programme: the Atrial Fibrillation Ablation Pilot Study, conducted by the European Heart Rhythm Association. Europace. 2012;14(8):1094-1103. 
75. Herrera Siklody C, Deneke T, Hocini M, et al. Incidence of asymptomatic intracranial embolic events after pulmonary vein isolation: comparison of different atrial fibrillation ablation technologies in a multicenter study. J Am Coll Cardiol. 2011;58(7):681-688.

76. Di Biase L, Gaita F, Toso E, et al. Does periprocedural anticoagulation management of atrial fibrillation affect the prevalence of silent thromboembolic lesion detected by diffusion cerebral magnetic resonance imaging in patients undergoing radiofrequency atrial fibrillation ablation with open irrigated catheters? Results from a prospective multicenter study. Heart Rhythm. 2014;11(5):791-798.

77. Gaita F, Leclercq JF, Schumacher B, et al. Incidence of silent cerebral thromboembolic lesions after atrial fibrillation ablation may change according to technology used: comparison of irrigated radiofrequency, multipolar nonirrigated catheter and cryoballoon. J Cardiovasc Electrophysiol. 2011;22(9):961-968.

78. Wissner E, Metzner A, Neuzil P, et al. Asymptomatic brain lesions following laserballoon-based pulmonary vein isolation. Europace. 2014;16(2):214-219.

79. Deneke T, Shin DI, Balta O, et al. Postablation asymptomatic cerebral lesions: long-term follow-up using magnetic resonance imaging. Heart Rhythm. 2011;8(11):1705-1711.

80. Rillig A, Meyerfeldt U, Tilz RR, et al. Incidence and long-term follow-up of silent cerebral lesions after pulmonary vein isolation using a remote robotic navigation system as compared with manual ablation. Circ Arrhythm Electrophysiol. 2012;5(1):15-21.

81. Martinek M, Sigmund E, Lemes C, et al. Asymptomatic cerebral lesions during pulmonary vein isolation under uninterrupted oral anticoagulation. Europace. 2013;15(3):325-331.

82. Neumann T, Kuniss M, Conradi G, et al. MEDAFI-Trial (Micro-embolization during ablation of atrial fibrillation): comparison of pulmonary vein isolation using cryoballoon technique vs. radiofrequency energy. Europace. 2011;13(1):37-44.

83. Schmidt B, Gunawardene M, Krieg D, et al. A prospective randomized single-center study on the risk of asymptomatic cerebral lesions comparing irrigated radiofrequency current ablation with the cryoballoon and the laser balloon. J Cardiovasc Electrophysiol. 2013;24(8):869-874.

84. Lickfett L, Hackenbroch M, Lewalter T, et al. Cerebral diffusionweighted magnetic resonance imaging: a tool to monitor the thrombogenicity of left atrial catheter ablation. J Cardiovasc Electrophysiol. 2006;17(1):1-7.

85. Wieczorek M, Lukat M, Hoeltgen R, et al. Investigation into causes of abnormal cerebral MRI findings following PVAC duty-cycled, phased RF ablation of atrial fibrillation. J Cardiovasc Electrophysiol. 2013;24(2):121-128.

86. Verma A, Debruyne P, Nardi S, et al. Evaluation and reduction of asymptomatic cerebral embolism in ablation of atrial fibrillation, but high prevalence of chronic silent infarction: results of the evaluation of reduction of asymptomatic cerebral embolism trial. Circ Arrhythm Electrophysiol. 2013;6(5):835-842.

87. Scaglione M, Blandino A, Raimondo C, et al. Impact of ablation catheter irrigation design on silent cerebral embolism after radiofrequency catheter ablation of atrial fibrillation: results from a pilot study. J Cardiovasc Electrophysiol. 2012;23(8):801-805.

88. Anselmino M, Scaglione M, Di Biase L, et al. Left atrial appendage morphology and silent cerebral ischemia in patients with atrial fibrillation. Heart Rhythm. 2014;11(1):2-7.

Vascular Health and Risk Management

\section{Publish your work in this journal}

Vascular Health and Risk Management is an international, peerreviewed journal of therapeutics and risk management, focusing on concise rapid reporting of clinical studies on the processes involved in the maintenance of vascular health; the monitoring, prevention and treatment of vascular disease and its sequelae; and the involvement of
89. Page SP, Siddiqui MS, Finlay M, et al. Catheter ablation for atrial fibrillation on uninterrupted warfarin: can it be done without echo guidance? J Cardiovasc Electrophysiol. 2011;22(3):265-270.

90. Gautam S, John RM, Stevenson WG, et al. Effect of therapeutic INR on activated clotting times, heparin dosage, and bleeding risk during ablation of atrial fibrillation. J Cardiovasc Electrophysiol. 2011;22(3):248-254.

91. Gopinath D, Lewis WR, Di Biase L, Natale A. Pulmonary vein antrum isolation for atrial fibrillation on therapeutic coumadin: special considerations. J Cardiovasc Electrophysiol. 2011;22(2):236-239.

92. Gaita F, Caponi D, Pianelli M, et al. Radiofrequency catheter ablation of atrial fibrillation: a cause of silent thromboembolism? Magnetic resonance imaging assessment of cerebral thromboembolism in patients undergoing ablation of atrial fibrillation. Circulation. 2010;122(17):1667-1673.

93. Lakkireddy D, Reddy YM, Di Biase L, et al. Feasibility and safety of uninterrupted rivaroxaban for periprocedural anticoagulation in patients undergoing radiofrequency ablation for atrial fibrillation: results from a multicenter prospective registry. J Am Coll Cardiol. 2014;63(10):982-988.

94. Kiss A, Nagy-Balo E, Sandorfi G, Edes I, Csanadi Z. Cerebral microembolization during atrial fibrillation ablation: comparison of different single-shot ablation techniques. Int J Cardiol. 2014;174(2): 276-281.

95. Kochhäuser S, Lohmann HH, Ritter MA, et al. Neuropsychological impact of cerebral microemboli in ablation of atrial fibrillation. Clin Res Cardiol. 2015;104(3):234-240.

96. Haeusler KG, Koch L, Herm J, et al. 3 Tesla MRI-detected brain lesions after pulmonary vein isolation for atrial fibrillation: results of the MACPAF study. J Cardiovasc Electrophysiol. 2013;24(1):14-21.

97. Park H, Hildreth A, Thomson R, O’Connell J. Non-valvular atrial fibrillation and cognitive decline: a longitudinal cohort study. Age Ageing. 2007;36(2):157-163.

98. Mavaddat N, Roalfe A, Fletcher K, et al. Warfarin versus aspirin for prevention of cognitive decline in atrial fibrillation: randomized controlled trial (Birmingham Atrial Fibrillation Treatment of the Aged Study). Stroke. 2014;45(5):1381-1386.

99. Barber M, Tait RC, Scott J, Rumley A, Lowe GD, Stott DJ. Dementia in subjects with atrial fibrillation: hemostatic function and the role of anticoagulation. J Thromb Haemost. 2004;2(11):1873-1878.

100. Flaker GC, Pogue J, Yusuf S, et al. Cognitive function and anticoagulation control in patients with atrial fibrillation. Circ Cardiovasc Qual Outcomes. 2010;3(3):277-283.

101. Price TR, Manolio TA, Kronmal RA, et al. Silent brain infarction on magnetic resonance imaging and neurological abnormalities in community-dwelling older adults. The Cardiovascular Health Study. CHS Collaborative Research Group. Stroke. 1997;28(6):1158-1164.

102. Hara M, Ooie T, Yufu K, et al. Silent cortical strokes associated with atrial fibrillation. Clin Cardiol. 1995;18(10):573-574.

103. Ritter MA, Dittrich R, Ringelstein EB. Klinisch stumme Hirninfarkte [Silent brain infarctions]. Nervenarzt. 2011;82(8):1043-1052. German.

metabolic disorders, particularly diabetes. This journal is indexed on PubMed Central and MedLine. The manuscript management system is completely online and includes a very quick and fair peer-review system, which is all easy to use. Visit http://www.dovepress.com/ testimonials.php to read real quotes from published authors. 